\title{
Metastatic Microsatellite Stable Colorectal Carcinoma
}

National Cancer Institute

\section{Source}

National Cancer Institute. Metastatic Microsatellite Stable Colorectal Carcinoma. NCI

Thesaurus. Code C142867.

A microsatellite stable carcinoma that arises from the colon or rectum and has metastasized to other anatomic sites. 